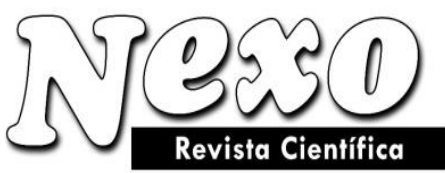

Vol. 34, No. 01, pp. 43-60/Marzo 2021

\title{
Design and development of the trailers optimal allocation and schedule model in the supply chain system with considering cross dock with stochastic planning
}

\author{
Diseño y desarrollo del modelo óptimo de asignación y cronograma de \\ remolques en el sistema de cadena de suministro con consideración de cross \\ dock con planificación estocástica
}

\author{
Javad Khamisabadi ${ }^{1}$, Mohammad Reza Kabaranzad Ghadim ${ }^{2 *}$, Hasan Ali Aghajani Kasegar ${ }^{3}$, and \\ Mohammad Mahdi Movahedi ${ }^{4}$ \\ ${ }^{1}$ Department of Industrial Management, College of Management, Firoozkooh Branch, Islamic Azad \\ University, Tehran, Iran \\ ${ }^{2}$ Department of Management, College of Management \& Accounting, Central Tehran Branch, Islamic \\ Azad University, Tehran, Iran \\ ${ }^{3}$ Department of Industrial Management, Faculty of Economics and Administrative Sciences, Mazandaran \\ University, Sari, Iran \\ ${ }^{4}$ Department of Industrial Management, College of Management, Firoozkooh, Islamic Azad University, \\ Tehran, Iran \\ "kabaranzad@yahoo.com
}

(recibido/received: 26-September-2020; aceptado/accepted: 05-December-2020)

\begin{abstract}
Todays, transportation, and logistics engineering processes are among the important issues of organizations in the competitive market. Considering the logistical structure of the logistics engineering and the more attention paid to the logistical tools and, in particular, such as the use of these tools, such as containers (pallets, containers, etc.), transportation equipment (trailer, forklift trucks, etc.), and The art of building the supply and distribution network concerning the main warehouses, cross-dock, and temporary storage, is one of the most critical and contemplative cases. In fact, all these tools work together to maximize system efficiency in the field of logistics concerning the leading impact indicators, including the time of shipment (loading, disloading, the allocation of trailers, etc.). This paper's main goal is to present and develop a mathematical model of trailer schedule planning in possible conditions in the cross-dock. In fact, the main function of this mathematical model is to minimize the total time of the logistics process from the stage of emptying the pallets from the materials producers in the cross docks and assigning the trailer to the door, and finally reloading the pallets to be distributed to the production sites. To solve this model and to analyze the outputs, mixed integer programming was used by GAMS software.
\end{abstract}

Keywords: Stochastic Schedule planning, Cross Dock, Logistics Engineering, Assign. 


\section{RESUMEN}

Hoy en día, los procesos de ingeniería de transporte y logística se encuentran entre los temas importantes de las organizaciones en el mercado competitivo. Teniendo en cuenta la estructura logística de la ingeniería logística y la mayor atención prestada a las herramientas logísticas y, en particular, como el uso de estas herramientas, como contenedores (pallets, contenedores, etc.), equipos de transporte (remolque, carretillas elevadoras, etc.), y El arte de construir la red de suministro y distribución con respecto a los almacenes principales, cross dock y almacenamiento temporal, es uno de los casos más importantes y contemplativos. De hecho, todas estas herramientas trabajan juntas para maximizar la eficiencia del sistema en el campo de la logística con respecto a los principales indicadores de impacto, incluido el tiempo de envío (carga, descarga, asignación de remolques, etc.). El objetivo principal de este artículo es presentar y desarrollar un modelo matemático de planificación de horarios de remolques en las posibles condiciones en el muelle de cruce. De hecho, la función principal de este modelo matemático es minimizar el tiempo total del proceso logístico desde la etapa de vaciado de los pallets de los productores de materiales en los cross docks y la asignación del remolque a la puerta y finalmente la recarga de los pallets a distribuir. a los sitios de producción. Para resolver este modelo y analizar las salidas, el software GAMS utilizó la programación de enteros mixtos.

Palabras clave: Planificación de horarios estocásticos, Cross Dock, Ingeniería logística, Asignar

\section{INTRODUCTION}

Cross-docking is a warehousing strategy that moves products through flow consolidation centers or cross docks without putting them into storage. It is normally considered a two-stage product flow where the first stage contains truckloads of mostly similar items from suppliers, called the inbound. The second stage contains truckloads of mostly different items to customers, called the outbound. Products are unloaded from incoming trailers ${ }^{1}$ and loaded onto outgoing trailers with little or no storage in between. To set up cross-docking, a big yard is required to accommodate incoming and outgoing trailers. The cross-dock itself is generally a rectangular dock (Bozer \& Carlo, 2008) with doors placed around its perimeter. Whenever an incoming truck arrives at the yard of a cross-dock, it is assigned to a dock door (or waits in a queue on the yard until it is assigned, Boysen et al., 2010), where inbound loads are unloaded and scanned to determine their intended destinations. The loads are then sorted, moved across the dock, and loaded onto outgoing trucks (or staged in load positions waiting for their outbound trailers to be assigned to dock door, Cohen \& Keren, 2008). Depending on its size or shape, freight (typically palletized) is moved from inbound trailers to outbound trailers by different material handling equipment, including forklifts, pallet jacks, and a conveyor belt system. In general, cross-docking helps reduce the supply chain inventory and transportation costs, thereby improving the organization's financial flows and profitability.

One of the primary means of reducing labor cost and congestion in a cross-docking terminal is truck scheduling, as it determines material flow patterns within the terminal and the resulting load on each material handling system. According to Gue (1995), by placing trailers in the correct doors, terminal managers avoid having workers travel too far, reduce worker and forklift congestion, and, hence, the total cross-docking operation time. Thus, the truck scheduling problem decides on the sequence of incoming and outgoing trucks at the cross-docking terminal's dock doors so that some performance criteria (like total cross-docking operation time) are met.

The variations in cross-docking operational characteristics result in different modeling and evaluation methodologies for the schedule of trucks. This paper studies the truck scheduling problem according to a 
cross-docking model, which has practical applications in the fast-moving consumer goods (FMCG) industry (Li et al., 2008) and military logistics (Li et al., 2008b). In this cross-docking scenario, trucks are assigned to dock doors on a daily basis to exchange some of their products before being dispatched to their customers. We aim at addressing the problem from a practical point of view by first proposing a realistic cross-docking model. Unlike a number of studies that model the cross-docking operation in an abstract way in the context of machine scheduling (Song \& Chen, 2007; Chen \& Lee, 2009; Chen \& Song 2009; Li et al., 2004; Alvarez-Perez et al., 2009) or assume an unlimited number of doors and forklifts (Tsui \& Chang 1990; Tsui \& Chang 1992; Bermudez \& Cole 2001; Lim et al., 2006; Ley \& Elfayoumy, 2007; Cohen \& Keren, 2009), this research emulates the real world cross-docking by defining pallets as the unit of shipments exchanged between the trailers and imposing constraints on the number of doors and forklifts as the cross-dock critical resources.

Furthermore, as normally desired by terminal managers, the allocation of doors and forklifts is considered non-preemptive throughout cross-docking. Non-preemptive door assignment incurs complexities in the feasibility of the studied truck scheduling problem. This is because the problem might be entrapped in deadlock, and no feasible solution is produced (see Section 3.1 for more explanation). The deadlock situation has also been observed in two independent works by Lim et al. (2006); Miao et al. (2009), and Shakeri et al. (2010). For the former, the authors suggest unfulfilled shipments to resolve the deadlock, which is not recommended in practice due to the high cost of keeping the shipments in the cross-dock (even for one additional day). For the latter, solution infeasibility is the outcome. The infeasibility occurs because the proposed heuristic is not robust in detecting and avoiding deadlock while scheduling trailers. Accordingly, there may be a feasible schedule for a given problem instance while the algorithm fails to find it.

The proposed algorithmic approach further supplements the practicality of our work. The aim is to develop an algorithm that can find feasible and fairly good solutions in a relatively short time and second that is simple to be implemented in an industrial setting. For this purpose, we propose a two-phase heuristic algorithm where in the first phase, a heuristic search is deployed to construct a feasible sequence of trucks for the assignment to dock doors, and in the second, a rule-based heuristic is used to assign each sequenced truck to a proper dock door, subject to a limited number of forklifts, such that significant savings in the total cross-docking operation time (or the truck schedule length) are achieved. We show that our heuristic algorithm is robust in finding feasible solutions with respect to the characteristics of the input data. The experimental data, though synthetically generated, mimic real-world problem instances. The data set includes problem instances of different levels of difficulty representing small cross docks hosting a few dozen trailers to huge ones hosting over 2000 trailers. The rest of the paper is organized as follows. Section 2 outlines the operational strategies considered in the cross-docking model from which an MIP model is developed to formulate the truck scheduling problem. Section 3 discusses the conditions that lead to the infeasibility of the truck scheduling problem. The findings are then used as the motivation for developing our two-phase heuristic algorithm. In Section 4, the methodology to generate synthetic data in the absence of real data is introduced. The proposed algorithm's efficiency in terms of deadlock avoidance and solution quality is evaluated and discussed in Section 5. The evaluation is conducted against the mathematical model's solutions and a sequencing heuristic proposed in (Shakeri et al., 2010) for a similar truck scheduling problem. The capability for augmenting the algorithm to a re-starting heuristic to construct a number of feasible trailer sequences for optimization purposes is also discussed and experimented. Finally, Section 6 concludes the paper and highlights our future research directions.

\section{CROSSDOCKING MODEL DEVELOPMENT}

Figure 1 presents the proposed cross-docking model where a number of trailers are cross-docked in a multiple-door cross-dock. Trailers are assigned to dock doors on a daily basis to exchange some of their products before being dispatched to their customers. (The exchange pattern is known in advance.) 
Products are staged onto staging areas until their destination trailers are docked in the cross-dock. Without loss of generality, we assume that the products whose destination trailers have not yet been assigned to an available door are temporarily staged in front of the doors that have been assigned their source trailers. The formation of staging areas is illustrated in Figure 1, based on Bartholdi and Gue's observation from real cross docks (Bartholdi \& Gue, 2004). As the figure shows, some space is reserved in front of each door to stage freight for that door.

This study employs synchronous cross-docking, which requires that all the trailers be available in the cross-dock yard before the cross-docking operation starts. Truck scheduling starts when the first trailer is assigned to a door and ends when the last trailer leaves its assigned door. As soon as a trailer is assigned to a free door, a worker unloads the exchanged products onto the staging area provided in front of the door. The products are then moved by forklifts and discharged onto the respective staging areas of the doors to which their destination trailers are assigned. Similar to unloading, a worker is dedicated to loading the exchanged products onto a destination trailer. Simply put, what is done inside the cross-dock is to unload, move, and load the exchanged products between the trailers.

\subsection{Truck scheduling formulation}

To formulate the truck scheduling problem addressed in this paper, it is required to sketch how products are exchanged among trailers in the cross-dock. This is explained by applying the following operational characteristics to the cross-docking model:

Products are packed in pallets where all the products in an exchanged pallet are destined to one destination trailer.

A trailer's unloading operations can be initiated as soon as it is assigned to a dock door.

The loading operations of a trailer can start only after its unloading operations are completed.

A trailer is ready to release its assigned door and leaves the cross-dock when its loading operations are completed.

Trailer change over time is the same for all trailers.

Pallets are unloaded or loaded by a worker one at a time. Also, only one worker can unload/load pallets from/onto a given trailer at any time.

A worker unloads or loads a pallet in a one-time unit.

Pallets are unloaded in sequence according to the order they have been placed at the supplier side and loaded according to the order they arrive at the destination door. (The former is input to the problem while the latter is determined during the cross-docking operation.) A forklift can move only one pallet per trip.

A forklift moves a pallet (from its origin door) to its destination door only if the recipient trailer has been assigned to that door.

The velocity of a forklift is assumed to be $1 \mathrm{~m}$ per second, making moving time and moving distance interchangeable. The distance between any two doors is equal to the distance between their respective staging areas. Pallets are moved in rectilinear paths due to the aisles created by staged freight (Gue, 1999). The space allocated in front of each door does not overflow as a result of staged freight. 


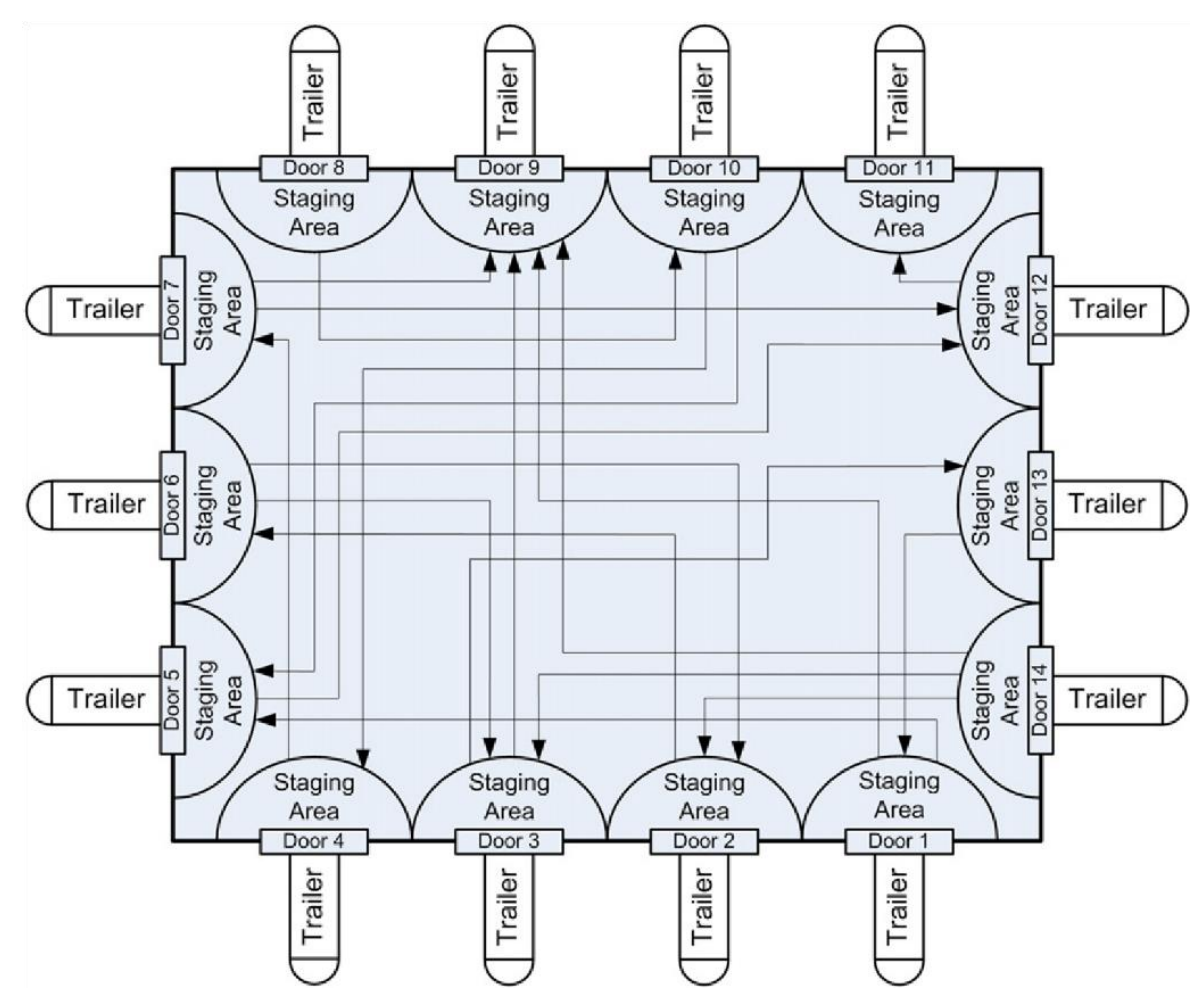

Figure 1: Structure and operation of the proposed cross-docking model.

The aforementioned cross-docking operations' functionality is subject to the availability of the cross-dock resources, including dock doors, forklifts, and workers, which are considered limited. The number of trucks in the cross-dock yard may exceed the number of doors, leading to queues of trucks waiting to be assigned to doors. (In this study, we define the ratio of the number of trucks to the number of doors as the trailer-to-door ratio and denote it by a.)

Likewise, there might be delays in pallet handling time due to the unavailability of workers and forklifts. If no worker is available, a delay should be incurred in the pallet unloading/loading time till one worker is available. Normally, these workers are the truck drivers themselves ( $\mathrm{Yu}, 2004)$, allowing the delays to be negligible. However, in terms of forklifts, the amount of delays depends on the total number of forklifts operating in the cross-dock and how they are scheduled for the service. If we assume one forklift is dedicated to each door for moving its unloaded products, respectively, then the forklift scheduling problem is reduced to the problem of scheduling the movements of every single forklift based on the scheduling conditions of only those trailers which are waiting to receive the unloaded pallets. A procedure can be embedded into the truck scheduling algorithm (see Section 3.2) to construct the pallets' moving order unloaded in front of each door to their respective destination doors. Having known the orders, the delays can be calculated straightforwardly on the proviso that no freight congestion nor interference among forklifts occurs to vary the forklift velocity. For example, for two pallets (unloaded at the same door) where the first one precedes the other in the moving order list, the latter should wait until the corresponding forklift moves the former to its destination door and then returns to the origin door. When the number of forklifts is fewer than the number of doors, the delays can be bounded by integrating a more complex forklift scheduling problem into the current problem. This is, however, beyond the scope of this paper so we assume the number of forklifts is equal to the number of doors.

The allocation of doors, forklifts, and workers is considered non-preemptive. In terms of doors, this means that a trailer does not release its assigned door unless it completes its operations (i.e., unloading/loading). They cannot be interrupted for another service forklifts and workers until they finish moving and 
unloading/loading their assigned pallet, respectively. Nonpreemptive door assignment makes it necessary to investigate the truck scheduling problem's feasibility before its optimality as the problem might be entrapped in deadlock and no feasible solution is produced. Accordingly, the truck scheduling problem studied in this paper is formulated as the problem of constructing a feasible sequence of trailers for the assignment to dock doors and assigning each sequenced trailer to a proper dock door, subject to a limited number of forklifts equal to the total number of doors, such that significant savings in the total crossdocking operation time (starts when the first trailer is assigned to a door till the last trailer leaves its assigned door) are achieved. The objective function, i.e., schedule length, is also referred to as makespan.

\subsection{Integer program}

The truck scheduling problem studied in this paper can be represented analytically in the context of an integer program. In the mixed integer programming (MIP) formulation, 9J9 trailers are waiting for crossdocking in a cross-dock of 9M9 doors. Their respective distances represent the location of the cross-dock doors. There are in total 9P9 pallets exchanged between the trailers. For any two trailers that exchange some of their products, a pallet unloaded from one of them is loaded onto the other. Accordingly, each trailer $\mathrm{j}$ has two sets of pallets. The first set contains those pallet IDs unloaded from the trailer ${ }^{2}$ (denoted by $\mathrm{U}_{\mathrm{j}}$ ), and the second contains those loaded onto the trailer (denoted by $\mathrm{L}_{\mathrm{j}}$ ). The following notation is used to describe the MIP model:

- $\quad j_{U i}$ - represents the unloading operation of pallet $\mathrm{i}$

- $j_{M i}$ - represents the moving operation of pallet $\mathrm{i}$

- $j_{L i}$ - represents the loading operation of pallet $\mathrm{i}$

- $m_{U i}$. represents resource i required for the unloading operation. (According to the problem definition, the resource is door i and its designated worker.)

- $m_{M i}$ - represents the resource i required for the moving operation. (According to the problem definition, the resource is forklift $\mathrm{i}$ designated to door i.)

- $m_{L i}$ - represents resource i required for the loading operation. (According to the problem definition, the resource is door i and its designated worker.)
m door,$m \in M=\{1, \ldots,|M|\}$
j Trailer,$j \in J-\{1, \ldots,|J|\}$
p pallet,$p \in P-\{1, \ldots,|P|\}$
$U_{j} \quad$ set of pallets unloaded from trailer $\mathrm{j}$
$L_{j} \quad$ set of pallets loaded onto trailer $\mathrm{j}$
$B_{p} \quad$ unloading position of pullet $\mathrm{p}$
$l^{U} \quad$ time taken to unload a pullet
$t_{p c m}^{M} \quad$ time taken to move a pallet from door $\mathrm{m}$ to door $\mathrm{m}$ '
$t^{L} \quad$ time taken to load u pallet
$T^{C} \quad$ Trailer change over time
$Q \quad$ a big umber not less than the worst schedule length

Decision variables 


\begin{tabular}{|c|c|}
\hline$O_{\max }$ & schedule length (or make span) \\
\hline$u_{j}$ & assignment time of trailer $\mathrm{j}$ \\
\hline$c_{j}$ & completion time of trailer $\mathrm{j}$ \\
\hline$\lambda_{p}$ & time when moving of pallet $\mathrm{p}$ starts \\
\hline$\mu_{p}$ & time when moving of pallet $\mathrm{p}$ is completed \\
\hline$\sigma_{p}$ & time when loading of pallet $\mathrm{p}$ is completed \\
\hline$\delta_{p p^{\prime}}$ & $\begin{array}{l}1 \text {, if. for pallets } p \text { and } p \text { 'staged onto the same staging area, } p \text { is moved } \\
\text { before } p \text { ', else } 0 \text { ) }\end{array}$ \\
\hline$T_{p u t}$ & $\begin{array}{l}\text { 1, if for pallets } \mathrm{p} \text { and } \mathrm{p}^{\prime} \text { loaded out the same trailer, } \mathrm{p} \text { is loaded before } \mathrm{p}^{\prime} \text {, } \\
\text { else } 0\end{array}$ \\
\hline$I_{j m}$ & 1 , if trailer $\mathrm{j}$ is assigned to door $\mathrm{m}$, else 0 \\
\hline$V_{j j}$ & 1, if, for trailers $\mathrm{j}$ and $\mathrm{j}$ ' assigned to the same door, $\mathrm{j}$ precedes $\mathrm{j}$ ', else 0 \\
\hline$q_{p}$ & $\begin{array}{l}1 \text {, if pallet } \mathrm{p} \text { is to be moved [by a forklift] before loaded onto its } \\
\text { destination trailer, else } 0\end{array}$ \\
\hline$V_{\text {jiojm }}$ & $\begin{array}{l}1 \text {, if trailer } \mathrm{j} \text { is assigned to door } \mathrm{m} \text { and trailer } \mathrm{j} \text { ' is assigned to door } \mathrm{m} \text { ', else } \\
0\end{array}$ \\
\hline$w_{p y}$ & $\begin{array}{l}\text { 1, if both pallets } \mathrm{p} \text { and } \mathrm{p} \text { ' are to be moved [by a forklift] before loaded onto } \\
\text { their destination trailers, else } 0\end{array}$ \\
\hline
\end{tabular}

With the above denotations and decision variables, the MIP formulation is as follows: Minimize $C_{\max }$

$$
\begin{aligned}
& S T \text {. } \\
& \sum_{m \in M} I_{j m}=l, j \in J
\end{aligned}
$$

Constraint (3.6) determines when the moving operation of a given pallet. Constraint (3.7) ensures that a pallet is loaded only after it is moved to its destination door. Constraint (3.8) indicates that a trailer can start its loading operations only after it completes its unloading operations Constraint (3.9) states that the loading operations of the pallets onto a given trailer are completed according to the order they arrive at the destination door Constraint (3.10) specifies that after loading its last pallet, a trailer is done and is ready to leave its assigned door. Constraint (3.11) defines the makespan, which is equal to the maximum completion time of the trailers.

Finally, binary variables $y_{j j^{\prime}}, \delta_{p p^{\prime}}, q_{p^{\prime}}, w_{p p^{\prime}}, \gamma_{p p^{\prime}}$, and $v_{j m j^{\prime} m^{\prime}}$ are used as the control variables in the mathematical formulation and defined by the following constraints: 


$$
\begin{aligned}
& a_{j} \geq c_{j}+\bar{F}^{c}-Q \cdot\left(1-v_{i j^{\prime}}\right), j, j^{\prime} \in J, j \neq j^{\prime} \\
& \lambda_{p} \geq a_{j}+t^{v} \cdot \beta_{\mu}, p \in U_{j}, j \in j^{\prime} \\
& \lambda_{p} \geq a_{j}, p \in L_{j}, j \in J
\end{aligned}
$$

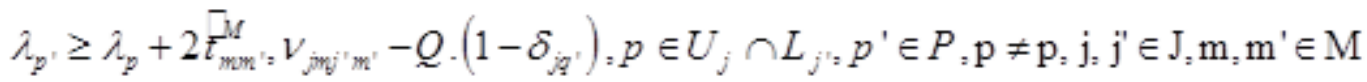

$$
\begin{aligned}
& \mu_{p} \geq \lambda_{p}+2 \bar{\tau}_{m m^{\prime},}^{M} V_{j m j^{\prime} m^{\prime}}, p \in U_{j} \cap L_{j}, \mathrm{j}, \mathrm{j}^{\prime} \in \mathrm{J}, \mathrm{m}, \mathrm{m}^{\prime} \in \mathrm{M} \\
& \sigma_{p} \geq \mu_{p}+\sqrt{t}, p \in P \\
& \sigma_{p} \geq \mu_{j}+\max _{p \in U}, \beta_{p^{\prime}}+\bar{t}^{t}, p \in L_{j}, j \in J \\
& \sigma_{p^{\prime}} \geq \sigma_{p}+\sqrt{t^{\underline{T}}}-\mathrm{Q} \cdot\left(1-\gamma_{p p^{\prime}}\right), p, p^{\prime} \in L_{j}, \mathrm{p} \neq \mathrm{p}^{\prime}, j \in J \\
& c_{j} \geq \sigma_{p}, p \in L_{j}, j \in J \\
& C_{\max } \geq C_{j}, j \in J \\
& v_{i j^{\prime}}+y_{j^{\prime} j}=\sum_{m \in M} v_{j j^{\prime}{ }^{\prime} m}=j, j^{\prime} \in J, j \neq j^{\prime} \\
& \delta_{p p^{\prime}}+\delta_{p^{\prime} p} \geq \sum_{m \in M} \leq v_{j m^{\prime} m}+Q \cdot\left(1-w_{z p p^{\prime}}\right) \cdot p \in U_{j}, p^{\prime} \in U_{j}, p \neq p^{\prime}, j, j^{\prime} \in J \\
& \delta_{p p^{\prime}}+\delta_{p^{\prime} p} \geq \sum_{m \in M} \leq v_{j m^{\prime} m}-Q \cdot\left(1-w_{p p^{\prime}}\right) \cdot p \in U_{j}, p^{\prime} \in U_{j}, p \neq p^{\prime} ; j, j^{\prime} \in J \\
& \delta_{p p^{\prime}} \leq q_{p^{\prime}} p, p^{\prime} \in P, p \neq p^{\prime} \\
& \delta_{p p^{\prime}} \leq q_{p^{\prime}} p, p^{\prime} \in P, p \neq p^{\prime} \\
& \mathrm{q}_{p} \leq \bar{\tau}_{m m^{\prime}}^{M}+Q \cdot\left(l-v_{j m j^{\prime} m^{\prime}}\right), p \in U, \cap L_{j}, j, j^{\prime} \in J, m, m^{\prime} \in M \\
& \mathrm{q}_{p} \leq \bar{t}_{m m^{\prime}}^{M}+Q-Q \cdot\left(l-v_{j m j^{\prime} m^{\prime}}\right), p \in U, \cap L_{j^{\prime}, j}, j^{\prime} \in J, m, m^{\prime} \in M \\
& w_{p p^{\prime}} \leq q_{p^{\prime}} \quad p, p^{\prime} \in P \\
& w_{p p^{\prime}} \leq q_{p^{\prime}} \quad p, p^{\prime} \in P \\
& w_{p p^{\prime}} \geq q_{p}+q_{p^{\prime}}-l, p, p^{\prime} \in P \\
& \gamma_{\mu p^{\prime}} \geq\left(\mu_{p^{\prime}}-\mu_{p}\right) / Q, p, p^{\prime} \in L_{j}, p \neq p^{\prime}, j \in J \\
& \gamma_{\mu p^{\prime}} \leq 1+\left(\mu_{p^{\prime}}-\mu_{p}\right) / Q, p, p^{\prime} \in L_{j}, p \neq p^{\prime}, j \in J \\
& v_{j m j^{\prime} m^{\prime}} \leq x_{j m}=j, j^{\prime} \in J, m \cdot m^{\prime} \in M \\
& v_{j m j^{\prime} m^{\prime}} \leq x_{j^{\prime} m^{\prime}=} j, j^{\prime} \in J, m . m^{\prime} \in M \\
& V_{j m j^{\prime} m^{\prime}} \geq x_{j m}+x_{j^{\prime} m^{\prime}}-1, j, j^{\prime} \in J, m . m^{\prime} \in M
\end{aligned}
$$

Constraint (3.1) ensures that each trailer is assigned early to one door. Constraint (3.2) defines the timing dependencies between two different trailers that have been assigned the same door. It states that the assignment time of a trailer to a door is after the other's loading completion time (which precedes the 
former trailer in being assigned to the same door) plus the time it takes to leave the door, that is. The trailer changeover time. Having been assigned to a door, ii trailer run start mid complete unloading pallets consecutively according to the position they have been placed at the supplier side. Constraints (3.3)-(3.5) specify the conditions required to be met before an unloaded pallet can be moved. Constraints (3.3) and (3.4) state that the movement of » pallet cannot be starlet! Unless it is unloaded and its destination trailer is assigned to an available door. Constraint (3.5) schedules the unloaded pallets' movement in front of a door according to the order, which itself is derided during the scheduling. Note that Constraint (3.5) implicitly emulates the situation where exactly one forklift is designated to one door for moving its singed pallets. For two pallets where the first one precedes the other in the moving order list, the bitter should wait until the corresponding forklift undo the former to its destination door and then returns to the origin door, on the value of a binary variable. Using indicator constraints, such relationships between a constraint and a variable can be directly expressed in the constraint declaration.

Thus, it is required to ensure that the value of $\mathrm{Q}$ is bigger than the maximal moving time and the maximal completion time difference between two moving operations. The value for $\mathrm{Q}$ can be calculated by adding all pallets' unloading and loading times together with all the possibilities for their moving times plus total trailer changeover times. The corresponding formula is described as follows:

$$
Q=\left(t^{U}+t^{L}+\sum_{m \in M} \sum_{m^{\prime} \in M} t_{m m^{\prime}}^{M}\right) \cdot|P|+T^{C} \cdot|J|
$$

Due to the fact that the processing time in the loading and unloading stages varies in reality, in this study, these two parameters were measured, and it was determined that each of the normal distribution is followed. The mean and variance of these two parameters are as follows:

The average time is taken to unload a pallet $=2$

Variance time is taken to unload a pallet $=0.25$

The average time is taken to load a pallet $=2$

Variance time is taken to load a pallet $=0.56$

In order to model, the random limit method is used which is presented in GAMES as follows:

$\operatorname{lambda}(\mathrm{p})=\mathrm{g}=\mathrm{a}(\mathrm{j})+(\operatorname{Atu} * \operatorname{beta}(\mathrm{p}))+(1.64 * \operatorname{beta}(\mathrm{p}) * \operatorname{sqrt}(\mathrm{Vtu}))$

$\operatorname{sigma}(\mathrm{P})=\mathrm{g}=\operatorname{miu}(\mathrm{p})+\mathrm{Atl}+(1.64 * \operatorname{sqrt}(\mathrm{Vtl}))$

$\operatorname{sigma}(\mathrm{p})=\mathrm{g}=\mathrm{a}(\mathrm{j})+\mathrm{Atu}+\mathrm{Atl}+(1.64 * \mathrm{sqrt}(\mathrm{Vtu}+\mathrm{Vtl}))$

After solving the model, it can be considered whether the answer is optimal or not, and the solver has managed to answer the model. 


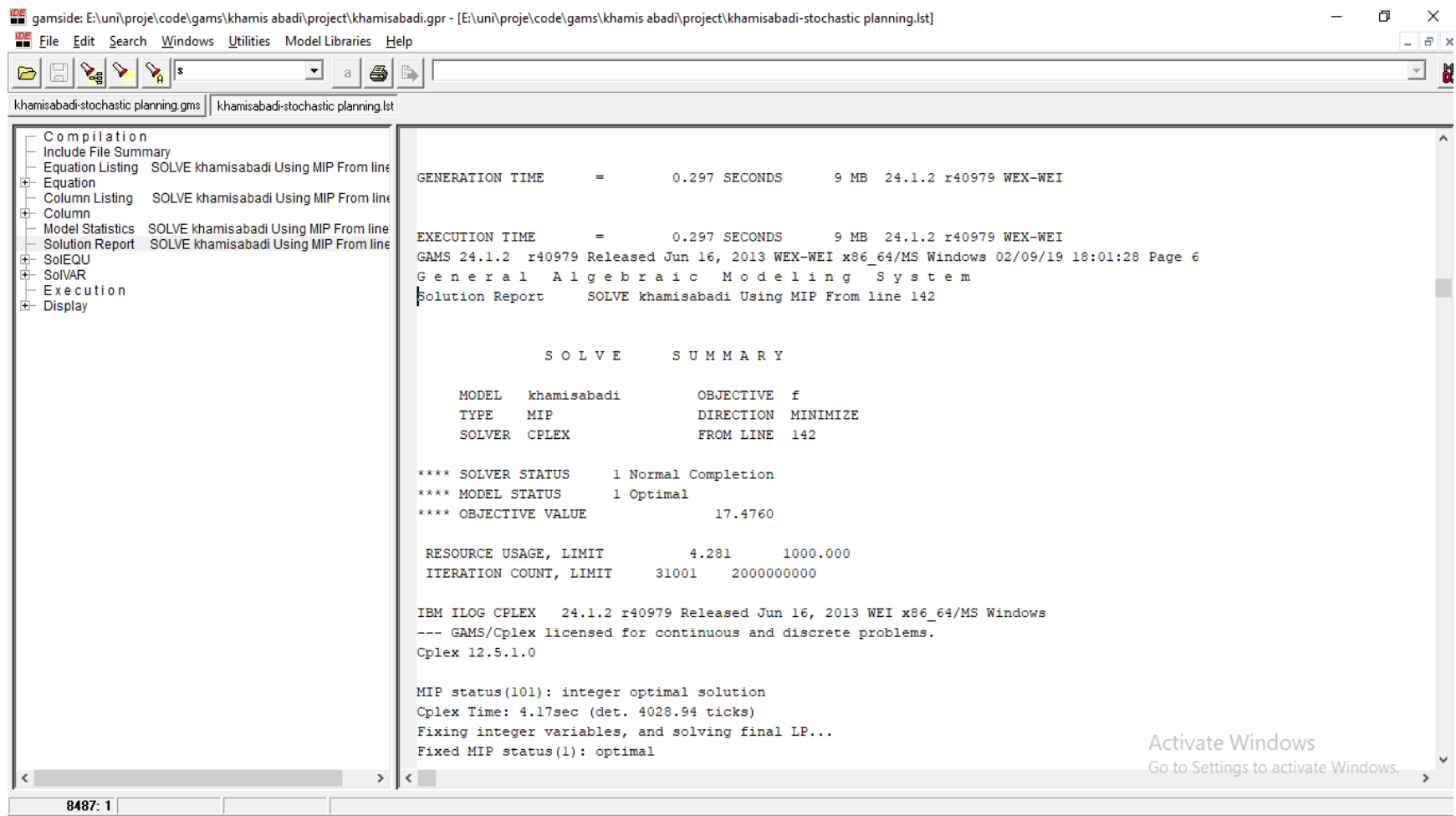

Figure 2. solving the model

According to figure 2, the solver state is normal, which means that the solver has solved the model without problems. On the other hand, the status of the model is OPTIMAL, which means the optimal solution is obtained (Table 1-9).

$\begin{array}{lll}\text { 145 VARIABLE f.L } & = & 17.476 \text { define name of goal } \\ \text { VARIABLE Cmax.L } & = & 17.476 \text { schedule length (or makespan) }\end{array}$

---- 145 VARIABLE a.L assignment time of trailer $\mathrm{j}$

j3 12.000, j7 12.000

--- 145 VARIABLE c.L completion time of trailer $\mathrm{j}$

j3 17.476, j4 14.275, j6 14.275, j7 17.476, j8 14.275

Table1. 145 VARIABLE lambda time when moving of pallet $\mathrm{p}$ starts

\begin{tabular}{|llllllrlrl|}
\hline $\mathrm{p} 1$ & 2.820, & $\mathrm{p} 2$ & 2.820, & $\mathrm{p} 3$ & 12.000, & $\mathrm{p} 4$ & 2.820, & $\mathrm{p} 5$ & 2.820 \\
\hline $\mathrm{p} 6$ & 2.820, & $\mathrm{p} 7$ & 2.820, & $\mathrm{p} 8$ & 12.000, & $\mathrm{p} 9$ & 2.820, & $\mathrm{p} 10$ & 12.000 \\
\hline $\mathrm{p} 11$ & 12.000, & $\mathrm{p} 12$ & 2.820, & $\mathrm{p} 13$ & 12.000, & $\mathrm{p} 14$ & 12.000, & $\mathrm{p} 15$ & 2.820 \\
\hline
\end{tabular}

Table2. 145 VARIABLE miu.L time when moving of pallet $\mathrm{p}$ is completed

\begin{tabular}{|llllllll|}
\hline p1 & 7.820, & p2 7.820, & p3 12.000, & p4 7.820, & p5 7.820 \\
\hline p6 7.820, & p7 7.820, & p8 12.000, & p9 7.820, & p10 12.000 \\
\hline p11 12.000, & p12 7.820, & p13 12.000, & p14 12.000, & p15 7.820 \\
\hline
\end{tabular}


Table 3. 145 VARIABLE sigma.L time when loading of pallet $\mathrm{p}$ is completed

\begin{tabular}{|lccccccccc|}
\hline $\mathrm{p} 1$ & 14.275, & $\mathrm{p} 2$ & 11.047, & $\mathrm{p} 3$ & 17.476, & $\mathrm{p} 4$ & 11.047, & $\mathrm{p} 5$ & 14.275 \\
\hline $\mathrm{p} 6$ & 14.275, & $\mathrm{p} 7$ & 11.047, & $\mathrm{p} 8$ & 17.476, & $\mathrm{p} 9$ & 14.275, & $\mathrm{p} 10$ & 17.476 \\
\hline $\mathrm{p} 11$ & 17.476, & $\mathrm{p} 12$ & 11.047, & $\mathrm{p} 13$ & 17.476, & $\mathrm{p}$ & 1417.476, & $\mathrm{p} 15$ & 14.275 \\
\hline
\end{tabular}

---- 145 VARIABLE delta.L 1, if, for pallets $\mathrm{p}$ and $\mathrm{pp}$ staged onto the same staging area, $\mathrm{p}$ is moved before p0, else 0 ( ALL 0.000 )

Table 4. 145 VARIABLE gamma. L 1, if, for pallets $\mathrm{p}$ and $\mathrm{pp}$ loaded onto the same trailer, $\mathrm{p}$ is loaded before $\mathrm{p} 0$, else 0

\begin{tabular}{|lcccl|}
\hline $\mathrm{p} 1$ & $\mathrm{p} 5$ & $\mathrm{p} 6$ & $\mathrm{p} 9$ & $\mathrm{p} 15$ \\
\hline $\mathrm{p} 2$ & & & 1.000 & 1.000 \\
\hline $\mathrm{p} 4$ & & & & 1.000 \\
\hline $\mathrm{p} 7$ & & & & 1.000 \\
\hline $\mathrm{p} 12$ & 1.000 & 1.000 & & \\
\hline
\end{tabular}

Table 5. 145 VARIABLE x.L 1 , if trailer $\mathrm{j}$ is assigned to door $\mathrm{m}$, else 0

\begin{tabular}{|c|c|c|c|c|c|c|}
\hline & $\mathrm{m} 1$ & $\mathrm{~m} 2$ & $\mathrm{~m} 3$ & $\mathrm{~m} 4$ & $\mathrm{~m} 5$ & $\mathrm{~m} 6$ \\
\hline j1 & & 1.000 & & & & \\
\hline $\mathrm{j} 2$ & & & & & & 1.000 \\
\hline $\mathrm{j} 3$ & & & & & 1.000 & \\
\hline j4 & & & & 1.000 & & \\
\hline $\mathrm{j} 5$ & & & & & 1.000 & \\
\hline j6 & & & 1.000 & & & \\
\hline j7 & & & & & & 1.000 \\
\hline j8 & 1.000 & & & & & \\
\hline
\end{tabular}

Table 6. 145 VARIABLE y.L 1, if, for trailers $\mathrm{j}$ and $\mathrm{jj}$ assigned to the same door, $\mathrm{j}$ precedes $\mathrm{j} 0$, else 0

\begin{tabular}{|lll|}
\hline & $\mathrm{j} 3$ & $\mathrm{j} 7$ \\
\hline $\mathrm{j} 2$ & & 1.000 \\
\hline $\mathrm{j} 5$ & 1.000 & \\
\hline
\end{tabular}

---- 145 VARIABLE q.L 1, if pallet $\mathrm{p}$ is to be moved [by a forklift] before loaded onto its destination trailer, else 0 (ALL 0.000 ) 
Table 7. 145 VARIABLE nou. $\mathrm{L} 1$, if trailer $\mathrm{j}$ is assigned to door $\mathrm{m}$ and trailer $\mathrm{j} 0$ is assigned to door $\mathrm{m} 0$, else 0

$\operatorname{INDEX} 1=\mathrm{j} 1$

\begin{tabular}{|c|c|c|c|c|c|c|}
\hline & & & & & & \\
\hline $\mathrm{m} 1$ & $\mathrm{~m} 2$ & $\mathrm{~m} 3$ & $\mathrm{~m} 4$ & $\mathrm{~m} 5$ & m6 & \\
\hline $\mathrm{m} 2 . \mathrm{j} 1$ & & 1.000 & & & & \\
\hline $\mathrm{m} 2 . \mathrm{j} 2$ & & & & & & 1.000 \\
\hline $\mathrm{m} 2 . \mathrm{j} 3$ & & & & & 1.000 & \\
\hline $\mathrm{m} 2 . \mathrm{j} 4$ & & & & 1.000 & & \\
\hline $\mathrm{m} 2 . \mathrm{j} 5$ & & & & & 1.000 & \\
\hline $\mathrm{m} 2 . \mathrm{j} 6$ & & & 1.000 & & & \\
\hline $\mathrm{m} 2 . j 7$ & & & & & & 1.000 \\
\hline $\mathrm{m} 2 . \mathrm{j} 8$ & 1.000 & & & & & \\
\hline
\end{tabular}

$\operatorname{INDEX} 1=\mathrm{j} 2$

\begin{tabular}{|c|c|c|c|c|c|c|}
\hline & $\mathrm{m} 1$ & $\mathrm{~m} 2$ & $\mathrm{~m} 3$ & $\mathrm{~m} 4$ & $\mathrm{~m} 5$ & $\mathrm{~m} 6$ \\
\hline $\mathrm{m} 6 . \mathrm{j} 1$ & & 1.000 & & & & \\
\hline m6.j2 & & & & & & 1.000 \\
\hline m6.j3 & & & & & 1.000 & \\
\hline m6.j4 & & & & 1.000 & & \\
\hline m6.j5 & & & & & 1.000 & \\
\hline m6.j6 & & & 1.000 & & & \\
\hline m6.j7 & & & & & & 1.000 \\
\hline m6.j8 & 1.000 & & & & & \\
\hline
\end{tabular}

$\operatorname{INDEX} 1=\mathrm{j} 3$

\begin{tabular}{|c|c|c|c|c|c|c|}
\hline & $\mathrm{m} 1$ & $\mathrm{~m} 2$ & $\mathrm{~m} 3$ & $\mathrm{~m} 4$ & $\mathrm{~m} 5$ & m6 \\
\hline m5.j1 & & 1.000 & & & & \\
\hline m5.j2 & & & & & & 1.000 \\
\hline m5.j3 & & & & & 1.000 & \\
\hline m5.j4 & & & & 1.000 & & \\
\hline m5.j5 & & & & & 1.000 & \\
\hline m5.j6 & & & 1.000 & & & \\
\hline $\mathrm{m} 5 . \mathrm{j} 7$ & & & & & & 1.000 \\
\hline m5.j8 & 1.000 & & & & & \\
\hline
\end{tabular}

$\operatorname{INDEX} 1=\mathrm{j} 4$

\begin{tabular}{|lrrrrrr|}
\hline & $\mathrm{m} 1$ & $\mathrm{~m} 2$ & $\mathrm{~m} 3$ & $\mathrm{~m} 4$ & $\mathrm{~m} 5$ & $\mathrm{~m} 6$ \\
\hline $\mathrm{m} 4 . \mathrm{j} 1$ & & 1.000 & & & & \\
\hline $\mathrm{m} 4 . \mathrm{j} 2$ & & & & & & 1.000 \\
\hline $\mathrm{m} 4 . \mathrm{j} 3$ & & & & & 1.000 & \\
\hline
\end{tabular}




\begin{tabular}{|lll|}
\hline$m 4 . j 4$ & 1.000 & \\
\hline$m 4 . j 5$ & \multicolumn{3}{c|}{1.000} \\
\hline$m 4 . j 6$ & 1.000 & \\
\hline$m 4 . j 7$ & & 1.000 \\
\hline$m 4 . j 8$ & 1.000 & \\
\hline
\end{tabular}

INDEX $1=\mathrm{j} 5$

\begin{tabular}{|c|c|c|c|c|c|c|}
\hline & $\mathrm{m} 1$ & $\mathrm{~m} 2$ & $\mathrm{~m} 3$ & $\mathrm{~m} 4$ & $\mathrm{~m} 5$ & $\mathrm{~m} 6$ \\
\hline m5.j1 & & 1.000 & & & & \\
\hline $\mathrm{m} 5 . \mathrm{j} 2$ & & & & & & 1.000 \\
\hline m5.j3 & & & & & 1.000 & \\
\hline $\mathrm{m} 5 . \mathrm{j} 4$ & & & & 1.000 & & \\
\hline m5.j5 & & & & & 1.000 & \\
\hline m5.j6 & & & 1.000 & & & \\
\hline $\mathrm{m5.j7}$ & & & & & & 1.000 \\
\hline m5.j8 & 1.000 & & & & & \\
\hline
\end{tabular}

$\operatorname{INDEX} 1=\mathrm{j} 6$

\begin{tabular}{|c|c|c|c|c|c|c|}
\hline & $\mathrm{m} 1$ & $\mathrm{~m} 2$ & $\mathrm{~m} 3$ & $\mathrm{~m} 4$ & $\mathrm{~m} 5$ & $\mathrm{~m} 6$ \\
\hline $\mathrm{m} 3 . \mathrm{j} 1$ & & 1.000 & & & & \\
\hline m3.j2 & & & & & & 1.000 \\
\hline $\mathrm{m} 3 . \mathrm{j} 3$ & & & & & 1.000 & \\
\hline m3.j4 & & & & 1.000 & & \\
\hline $\mathrm{m} 3 . \mathrm{j} 5$ & & & & & 1.000 & \\
\hline m3.j6 & & & 1.000 & & & \\
\hline $\mathrm{m} 3 . \mathrm{j} 7$ & & & & & & 1.000 \\
\hline $\mathrm{m} 3 . \mathrm{j} 8$ & 1.000 & & & & & \\
\hline
\end{tabular}

$\operatorname{INDEX} 1=\mathrm{j} 7$

\begin{tabular}{|c|c|c|c|c|c|c|}
\hline & $\mathrm{m} 1$ & $\mathrm{~m} 2$ & $\mathrm{~m} 3$ & $\mathrm{~m} 4$ & $\mathrm{~m} 5$ & $\mathrm{~m} 6$ \\
\hline m6.j1 & & 1.000 & & & & \\
\hline m6.j2 & & & & & & 1.000 \\
\hline m6.j3 & & & & & 1.000 & \\
\hline m6.j4 & & & & 1.000 & & \\
\hline m6.j5 & & & & & 1.000 & \\
\hline m6.j6 & & & 1.000 & & & \\
\hline m6.j7 & & & & & & 1.000 \\
\hline m6.j8 & 1.000 & & & & & \\
\hline
\end{tabular}


$\operatorname{INDEX} 1=\mathrm{j} 8$

\begin{tabular}{|c|c|c|c|c|c|c|}
\hline & $\mathrm{m} 1$ & $\mathrm{~m} 2$ & $\mathrm{~m} 3$ & $\mathrm{~m} 4$ & $\mathrm{~m} 5$ & $\mathrm{~m} 6$ \\
\hline $\mathrm{m} 1 . \mathrm{j} 1$ & & 1.000 & & & & \\
\hline $\mathrm{m} 1 . \mathrm{j} 2$ & & & & & & 1.000 \\
\hline $\mathrm{m} 1 . \mathrm{j} 3$ & & & & & 1.000 & \\
\hline $\mathrm{m} 1 . \mathrm{j} 4$ & & & & 1.000 & & \\
\hline $\mathrm{m} 1 . \mathrm{j} 5$ & & & & & 1.000 & \\
\hline m1.j6 & & & 1.000 & & & \\
\hline $\mathrm{m} 1 . \mathrm{j} 7$ & & & & & & 1.000 \\
\hline m1.j8 & 1.000 & & & & & \\
\hline
\end{tabular}

---- 145 VARIABLE w.L 1, if both pallets $\mathrm{p}$ and $\mathrm{p} 0$ are to be moved [by a fork lift] before loaded onto their destination trailers, else 0 ( ALL 0.000 )

---- 145 PARAMETER QM $=756.000$ a big number not less than the worst schedule length

Table 8. 145 PARAMETER $U$ set of pallets unloaded from trailer $\mathrm{j}$

\begin{tabular}{|c|c|c|c|c|c|c|}
\hline & $\mathrm{p} 1$ & $\mathrm{p} 2$ & p3 & $\mathrm{p} 4$ & $\mathrm{p} 5$ & p6 \\
\hline $\mathrm{j} 1$ & 1.000 & 1.000 & & 1.000 & & \\
\hline $\mathrm{j} 2$ & & & 1.000 & & & \\
\hline j5 & & & & & 1.000 & 1.000 \\
\hline+ & p7 & p8 & p9 & $\mathrm{p} 10$ & p11 & $\mathrm{p} 12$ \\
\hline $\mathrm{j} 1$ & 1.000 & & & & & 1.000 \\
\hline $\mathrm{j} 2$ & & & 1.000 & 1.000 & & \\
\hline j5 & & 1.000 & & & 1.000 & \\
\hline+ & p13 & p14 & p15 & & & \\
\hline $\mathrm{j} 2$ & & 1.000 & 1.000 & & & \\
\hline j5 & 1.000 & & & & & \\
\hline
\end{tabular}


Table 9. 145 PARAMETER L set of pallets loaded onto trailer $\mathrm{j}$

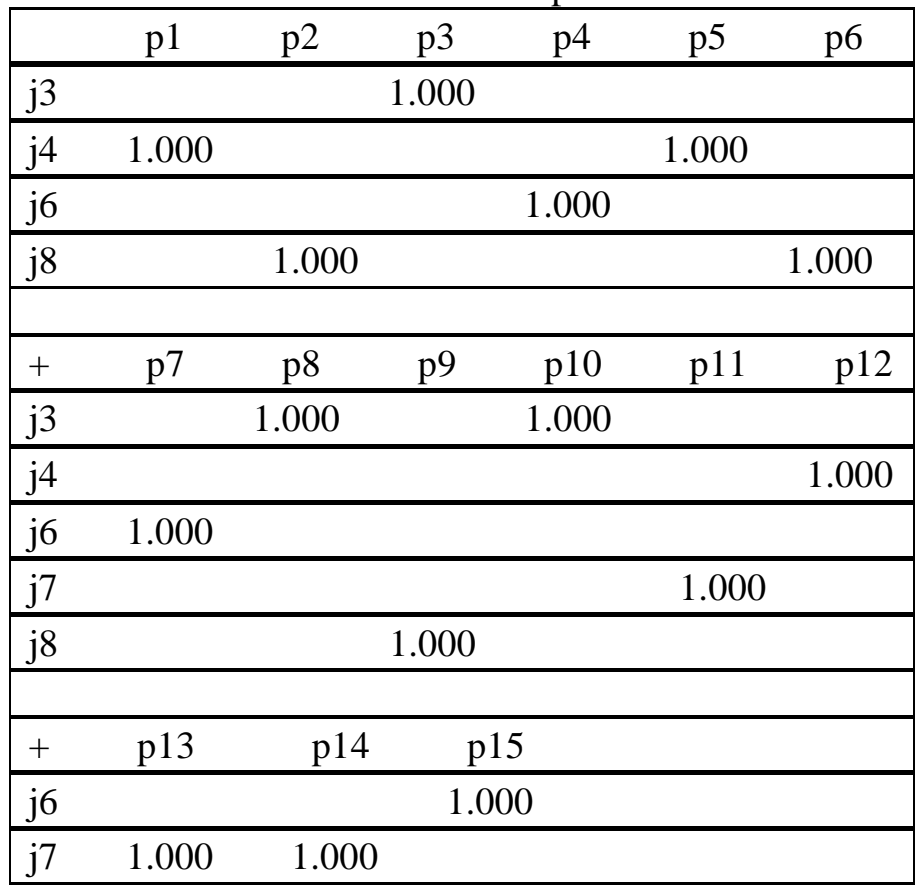

\section{CONCLUSION}

This paper addressed the truck scheduling problem in a cross-docking terminal whose resources, including doors, forklifts, and workers, were assumed limited and non-preemptive. While having practical instances in the broad scope of the FMCG industry and military logistics, the cross-docking model was purposefully specialized to visualize truck scheduling in the context of an integer program. Since non-preemptive door assignment incurs complexities in the problem feasibility, we developed an algorithmic approach capable of establishing solution feasibility for truck scheduling problem instances of various types and difficulty levels, which at the same time can be readily implemented in an industrial setting. From the modeling point of view, the intermediate storage in the cross-dock is not unlimited and should be represented by a number of limited staging areas distributed along with the dock doors.

Shakeri et al. [2011] conducted an analysis to investigate whether the cross-dock capacity is a bottleneck resource in the operation of truck scheduling or not. Having set up realistic values for the capacity of staging areas available in front of doors, the analysis showed that the entire cross-dock capacity never overflows. Nonetheless, it was observed that the allocated space in front of doors might overrun the assigned limit. It is thus required to avoid space overrun while truck scheduling is in progress. An effective strategy is to concurrently monitor the number of products staged in front of each door. In case an overrun occurs, a procedure is invoked to move the excess load to the appropriate locations where sufficient space is available. A post-processing procedure can also be used to balance the number of staged products in front of each door by utilizing forklift idle times. The utilization may even help to reduce the makespan by pre-moving pallets to their destination doors.

An intelligent randomization function is then designed to choose the rules for ranking the clusters based on the status of the search. In other words, the selection of each ranking function is subject to a probability whose value is dynamically updated by the history of the search. This indicates that the initial cluster's choice is adaptive (and not deterministic) to the input data. The important issue is defining and adjusting the ranking criteria of the functions such that they continually complement each other throughout the 
search. This can be extended to form a pool of good-quality feasible solutions of diverse attributes as the initial solutions of a neighborhood search method (such as a local search) to establish optimality.

\section{REFERENCES}

Alvarez-Perez, G.A., Gonzalez-Velarde, J.L., \& Fowler, J.W. (2009). Crossdocking-just in time scheduling: an alternative solution approach. Journal of the Operational Research Society, 60(4), 554-64.

Bartholdi, J., \& Gue, K. (2004). The best shape for a crossdock. Transportation Science, 38(2), 235-44.

Bermudez, R., \& Cole, M. (2001). A genetic algorithm approach to door assignments in break-bulk terminals. Technical Report MBTC-1102, Mack Blackwell Transportation Center, University of Arkansas, Fayetteville, AR.

Boysen, N., Fliedner, M., \& Scholl, A. (2010). Scheduling inbound and outbound trucks at cross docking terminals. OR Spectrum, 32(1), 135-61.

Bozer, Y.A., \& Carlo, H.J. (2008). Optimizing inbound and outbound door assignments in less-thantruckload crossdocks. IIE Transactions, 40(11), 1007-18.

Chen, F., \& Lee, C.Y. (2009). Minimizing the makespan in a two-machine cross-docking flow shop problem. European Journal of Operational Research, 193(1), 59-72.

Chen, F., \& Song, K. (2009). Minimizing makespan in two-stage hybrid cross docking scheduling problem. Computers \& Operations Research, 36(6), 2066-73.

Cohen, Y., \& Keren, B. (2008). A simple heuristic for assigning doors to trailers in crossdocks. In: International conference on industrial logistics (ICIL 2008): logistics in a flat world: strategy, management and operations. Tel Aviv, Israel (Occupied Palestine), 1-14.

Cohen, Y., \& Keren, B. (2009). Trailer to door assignment in a synchronous cross-dock operation. International Journal of Logistics Systems \& Management, 5(5), 574-90.

Gue, K. (1995). Freight terminal layout and operations. PhD thesis. Georgia Institute of Technology, Atlanta, GA.

Gue, K. (1999). The effects of trailer scheduling on the layout of freight terminals. Transportation Science, 33(4), 419-28.

Ley, S., \& Elfayoumy, S. (2007). Cross dock scheduling using genetic algorithms. In: International symposium on computational intelligence in robotics and automation. Jacksonville, FL, 20-22 June. ISBN 978-1-4244-0789-7, 540-44.

Li, Y., Lim, A., \& Rodrigues, B. (2004). Crossdocking-JIT scheduling with time windows. Journal of the Operational Research Society, 55(12), 1342-51.

Li, Z., Low, M.Y.H., Sim, C.H., \& Lim, Y.G. (2008). Optimal product allocation for crossdocking and warehousing operations in FMCG supply chain. In: IEEE international conference on service operations and logistics, and informatics, vols 1-2. Beijing, China, 12-15, 2963-8. 
Li, Z., Sim, C.H., He, W., \& Chen, C.C. (2008b). A solution for cross-docking operations planning, scheduling and coordination. In: IEEE international conference on service operations and logistics, and informatics, vols 1-2. Beijing, China, 12-15 October, 2957-62.

Lim, A., Ma, H., \& Miao, Z. (2006). Truck dock assignment problem with time windows and capacity constraint in transshipment network through crossdocks. In: International conference on computational science and its applications (ICCSA 2006), Part 3, 3982, 688-97.

Lim, A., Ma, H., \& Miao, Z. (2006). Truck dock assignment problem with operational time constraint within crossdocks. In: 19th International conference on industrial, engineering and other applications of applied intelligent systems, vol 4031. Annecy, France, 27-30 June, ISBN 3-540-35453-0, pp. 262-71.

Miao, Z., Lim, A., \& Ma, H. (2009). Truck dock assignment problem with operational time constraint within crossdocks. European Journal of Operational Research, 192(1), 105-15.

Shakeri, M. (2011). Truck scheduling problem in logistics of crossdocking. Technical Report NTU-SCE1101, Nanyang Technological University;, /http:// pdcc.ntu.edu.sg/content/mojtaba-shakeriS.

Shakeri, M., Low, M.Y.H., \& Lee, E.W. (2010). Development of a novel resource-constrained crossdocking model for the truck scheduling problem. In: IEEE international conference on emerging technologies and factory automation. Bilbao, Spain, 10.1109/ETFA.2010.5641166.

Shakeri, M., Low, M.Y.H., Li, Z., \& Lee, E.W. (2010). Two efficient constructive heuristics for scheduling trucks at crossdocking terminals. In: IEEE international conference on service operations and logistics, and informatics. Qingdao, Shandong, China, 177-82.

Song, K., \& Chen, F. (2007). Scheduling cross docking logistics optimization problem with multiple inbound vehicles and one outbound vehicle. In: IEEE international conference on automation and logistics, 1-6. Jinan, China, 18-21 August. ISBN 978-1-4244-1530-4, 3089-3094.

Tsui, L.Y., \& Chang, C.H. (1990). A microcomputer based decision support tool for assigning dock doors in freight yards. Computers \& Industrial Engineering, 19(1-4), 309-12.

Tsui, L.Y., \& Chang, C.H. (1992). An optimal solution to a dock door assignment problem. Computers \& Industrial Engineering, 23(1-4), 283-6.

\section{SEMBLANCE OF THE AUTHORS}

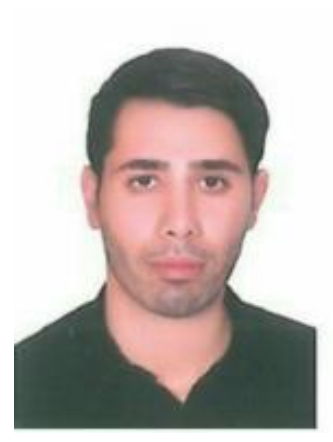

Javad Khamisabadi is a Ph.D student, Faculty of Management, Firuzkuh Branch, Islamic Azad University, Tehran, Iran. Presently working as a Logistics Engineer in IKCO and CEO of LEMHO in Iranian Business Holding. Presently trying to attend University to get his $\mathrm{PhD}$ in Industrial Management. He has attained professional experience of high quality doing lots of research projects on different aspects of Logistics management and Engineering. His research interests are principles of Logistics Optimization and Networking issues. 


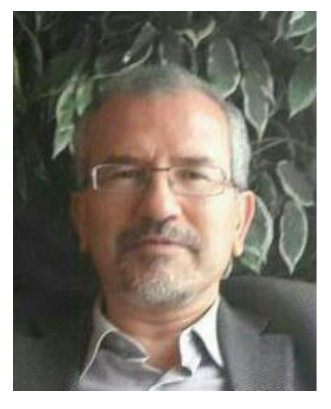

Mohammad Reza Kabaranzad Ghadim is Associated Professor, Faculty of Management, Central Tehran Branch, Islamic Azad University, Tehran, Iran. Presently working as an Associated Professor in Department of Management in Islamic Azad University, Central Tehran Branch. He has attained professional experience of high quality working with different groups of scholars in the field of management. His research interests are Logistics and Production Engineering and management, Entrepreneurship Management, Business and Marketing Management.

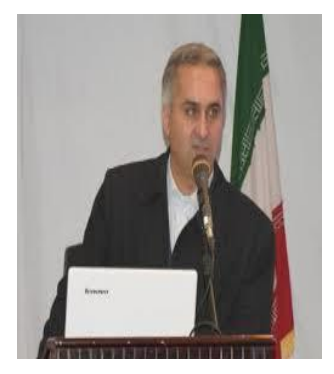

Hasan Ali Aghajani Kasegar is a Professor, Faculty of Management, Mazandaran University, Iran. Presently working as a Professor in Department of Management in Mazandaran University. He has attained professional experience of high quality working with different groups of scholars in the field of management. His research interests are in Logistics and Production Engineering and Management, Human Resource Management, Entrepreneurship Management, Business Management and Marketing.

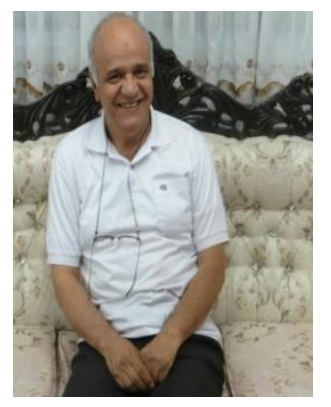

Mohammad Mahdi Movahedi is an Assistant Professor, Faculty of Management, Firuzkuh Branch, Islamic Azad University, Tehran, Iran. Presently working as Assistant Professor in Department of Industrial Management in Firuzkuh University. $\mathrm{He}$ has attained professional experience of high quality working with different groups of scholars in the field of management. His research interests are in Logistics and Production Engineering and Management, Maintenance, Business Management and Marketing. 